\title{
Transition from somatic embryo to friable embryogenic callus in cassava: dynamic changes in cellular structure, physiological status, and gene expression profiles
}

\author{
Qiuxiang Ma, Wenzhi Zhou and Peng Zhang *
}

\section{OPEN ACCESS}

Edited by:

Agnieszka Ludwików,

Adam Mickiewicz University, Poland

Reviewed by:

Taras P. Pasternak,

Albert-Ludwigs-Universität Freiburg,

Germany

Leena Tripathi,

International Institute of Tropical

Agriculture, Kenya

Wen-Wu Guo,

Huazhong Agricultural University,

China

${ }^{*}$ Correspondence:

Peng Zhang,

Institute of Plant Physiology and

Ecology, Shanghai Institutes for

Biological Sciences, Chinese

Academy of Sciences, 300 Fenglin

Road, 200032 Shanghai, China

zhangpeng@sibs.ac.cn

Specialty section:

This article was submitted to

Plant Biotechnology,

a section of the journal

Frontiers in Plant Science

Received: 31 July 2015 Accepted: 22 September 2015

Published: 06 October 2015

Citation:

Ma Q, Zhou W and Zhang P (2015)

Transition from somatic embryo to friable embryogenic callus in cassava: dynamic changes in cellular structure,

physiological status, and gene expression profiles.

Front. Plant Sci. 6:824.

doi: 10.3389/fpls.2015.00824
National Key Laboratory of Plant Molecular Genetics, Institute of Plant Physiology and Ecology, Shanghai Institutes for Biological Sciences, Chinese Academy of Sciences, Shanghai, China

Friable embryogenic callus (FEC) is considered as the most suitable material for efficient genetic transformation of cassava. Heavy genotype dependence of FEC induction and amenability to somaclonal variation limits the production and maintenance of reliable FEC. Identifying key elements involved in biological processes from somatic embryos (SEs) to FEC at different stages provides critical insights for FEC improvement. Cytological observation showed a dramatic change of subcellular structures among SEs, fresh FEC (FFEC), and old FEC (OFEC). Decrease of sucrose and increase of fructose and glucose were detected in OFEC. A total of 6871 differentially expressed genes (DEGs) were identified from SEs, FFEC, and OFEC by RNA-seq. Analysis of the DEGs showed that FEC induction was accompanied by the process of dedifferentiation, whereas the epigenetics modification occurred during the continuous subculturing process. The cell structure was reconstructed, mainly including the GO terms of "cell periphery" and "external encapsulating structure"; in parallel, the internal mechanisms changed correspondingly, including the biological process of glycolysis and metabolisms of alanine, aspartate, and glutamate. The significant reduction of genomic DNA methylation in OFEC indicated altered gene expression via chromatin modification. These results indicate that the induction and long-term subculture of FEC is a complicated biological process involving changes of genome modification, gene expression, and subcellular reconstruction. The findings will be useful for improving FEC induction and maintenance from farmer-preferred cassava cultivars recalcitrant to genetic transformation, hence improving cassava through genetic engineering.

\footnotetext{
Keywords: Manihot esculenta Crantz, somatic embryo, friable embryogenic callus, RNA-seq, somaclonal
} variation, DNA methylation, ploidy

\footnotetext{
Abbreviations: DEG, differentially expressed gene; FEC, friable embryogenic callus; FFEC, fresh FEC; GO, Gene Ontology; HPLC, high-performance liquid chromatography; OFEC, old FEC; qRT-PCR, real-time reverse transcription-polymerase chain reaction; RNA-seq, RNA sequencing; SE, somatic embryo; TEM, transmission electron microscopy; TF, transcription factor.
} 


\section{Introduction}

Cassava (Manihot esculenta Crantz) is widely cultivated in tropical and subtropical regions as an important source of food, feed, and industrial materials (Nassar and Ortiz, 2009; Sayre et al., 2011; Beeching, 2013). Because of high genetic heterozygosity, few flowers, low pollen fertility and fruit set rate, self-incompatibility, and serious trait separation in progeny, the conventional breeding of cassava is seriously hindered (Ceballos et al., 2010, 2012). Genetic engineering is an alternative effective method used to introduce value-adding genes to modify important agronomic traits (Taylor et al., 2004; Liu et al., 2011; Sayre et al., 2011). The friable embryogenic callus (FEC)-based genetic transformation is reported to be the most successful system in this decade (Raemakers et al., 1996; Schöpke et al., 1996; Taylor et al., 1996, 2004; Zhang et al., 2000; Bull et al., 2009; Liu et al., 2011; Xu et al., 2013).

FEC induction in cassava is a complicated process compared with the transformation protocols of many other species (Zhang and Gruissem, 2004; Bull et al., 2009). The process includes several steps as follows: primary somatic embryo (SE) induction, secondary SE multiplication, fresh FEC (FFEC) induction, and FEC subculturing and multiplication (Zhang, 2000). In cassava, primary and secondary SEs are easily achieved by incubating explants such as young leaf lobes or isolated shoot apexes in a culture medium supplemented with a auxin-like herbicide such as picloram or 2,4-D. Under a suitable condition, FFEC clusters can be induced from secondary SEs by continuous incubation on a GD medium supplemented with $50 \mu \mathrm{M}$ picloram, a process that is well-established and demonstrated in the model cultivar TMS60444 (Taylor et al., 1996; Bull et al., 2009). However, the FEC induction originating from SEs is a bottleneck and is greatly genotype dependent (Liu et al., 2011). Only recently, cultivars beyond TMS60444 could be used for FEC induction and genetic transformation, such as African farmer-preferred cultivars TME7, TME14, TME204, Ebwanatereka, Kibandameno, and Serere (Vanderschuren et al., 2012; Zainuddin et al., 2012; Chetty et al., 2013; Nyaboga et al., 2013, 2015; Chauhan et al., 2015). For Asian cultivars, the FECs of KU50, SC8, and SC205 were successfully induced in Shanghai Center for Cassava Biotechnology although the efficiency still needs to be improved in comparison with TMS60444. Nevertheless, severe somaclonal variation of regenerated plants from FECs after a short-term subculture (in 3 months) makes the process laborious and limits its application (Raemakers et al., 2001; Taylor et al., 2001, 2004; Bull et al., 2009). Understanding the regulatory mechanisms leading to the initiation of FEC from SEs and somaclonal variation in FEC is an essential step for improving the system.

Various factors including explant types, basic media, and hormones that affect SEs and the FEC induction process have been investigated by various tissue culture techniques (Reviewed by Liu et al., 2011). Recently, the studies optimizing the FEC transformation platform in several farmer-preferred cassava cultivars have made great progress (Zainuddin et al., 2012; Chetty et al., 2013; Chauhan et al., 2015). However, the changes of cellular structures and physiological status from SEs to the
FEC culture process are largely unknown, and less regulatory information is available at the molecular level. Previous studies indicate that SEs of cassava have a multicellular origin, and embryogenic masses are formed around the procambium (Baba et al., 2008). It will be useful to identify some cues to analyze the possibility of FEC induction and to evaluate the potential of FEC transformation.

In cassava, the decrease in regeneration ability and the increase in abnormal morphology of regenerated plants prevent the usage of old FEC (OFEC) that has a long-term in vitro culturing process. Many reasons might induce the occurrence of somaclonal variation during the tissue culture process, including irregular cell cycle, DNA methylation ratio change, ploidy change, etc. (Fraga and Esteller, 2002; Chakrabarty et al., 2003; Bairu et al., 2011; Miguel and Marum, 2011; Rival et al., 2013). In cassava, the ploidy levels of in vitro plantlets originating from stem cuttings treated with colchicine and oryzalin or regenerated from cotyledons of cassava SEs were assessed by the flow cytometry technique (Awoleye et al., 1994; Hankoua et al., 2005). The origin of anther-derived calli was assessed in cassava for their ploidy levels (Perera et al., 2014). With developing secondgeneration sequencing technologies, using the transcriptomic studies of somatic embryogenesis to identify the key factors that change during somatic embryogenesis and callus induction has become a fast and useful practical tool in various plants, for example, maize, oil palm, and longan (Lin et al., 2009; Lai and Lin, 2013; Salvo et al., 2014).

To better understand the molecular changes in the process of cassava FEC induction and subculturing, the gene expression profiles of SEs, FFEC, and OFEC were characterized using the RNA-seq technology. The major pathways and key events related to these representative materials of FEC development were illustrated by the deep analysis of differentially expressed genes (DEGs). In combination with the histological and chemical analysis during the FEC formation process, the understanding of the molecular regulatory and networks regulating FEC formation and subculture process has increased, which could provide guidance toward improving FEC induction from recalcitrant cultivars as well as ensuring the quality of regenerated plants through improved culture conditions.

\section{Materials and Methods}

\section{Plant Materials used for Solexa Sequencing}

The cassava cultivar TMS60444 was used as a plant material for SEs and FEC induction according to the method described in a previous study (Zhang and Gruissem, 2004). Briefly, SEs were induced from shoot apical meristems and axillary buds on CIM (MS medium, Murashige and Skoog, 1962 with 2\% sucrose and $2 \mu \mathrm{M} \mathrm{CuSO} 4,12 \mathrm{mg} / \mathrm{l}$ picloram, solidified with $0.6 \%$ agar, $\mathrm{pH}$ 5.8) in the dark and subcultured every 2 weeks. Four to six-week-old SEs were transferred onto the GD medium (GD salts and vitamins Gresshoff and Doy, 1974, $12 \mathrm{mg} / \mathrm{l}$ picloram, $2 \%$ sucrose, $0.5 \%$ agar, $\mathrm{pH} 5.8)$ at $(26 \pm 2)^{\circ} \mathrm{C}$ in dark for FFEC induction. When FFEC appeared, it was transferred onto a fresh GD medium and cultivated at $(26 \pm 2)^{\circ} \mathrm{C}$ with a $16 \mathrm{~h}$ 
photoperiod of weak light $\left(\sim 10 \mu \mathrm{mol} / \mathrm{m}^{2} \mathrm{~s}\right)$ and subcultured at 3 week intervals. Two-week-old SEs cultured on a GD medium, FFEC emerging from SEs, and 9 month-old OFEC were used for analysis.

\section{Histological Observation by Cross Section and Transmission Electronic Microscopy (TEM)}

The SE, FFEC, and OFEC samples were collected and fixed in formalin-acetic acid-alcohol (FAA, 10:5:50\%) for $48 \mathrm{~h}$ at $4^{\circ} \mathrm{C}$ and then embedded in paraffin wax. Sections of $15 \mu \mathrm{m}$ thickness were cut and placed on silane-coated slides to fix the samples. After drying overnight at $37^{\circ} \mathrm{C}$, the samples were deparaffinized and stained with hematoxylin and eosin solution. TUNEL and DAPI were used to counter-stain nuclei before the last washing for $5 \mathrm{~min}$. All pictures were taken using a fluorescent microscope (Olympus BX51, Olympus Optical, Tokyo, Japan) with differential interference contrast using appropriate filters. For TEM analysis, the fixed tissue was washed, and fixed with $1 \%$ $\mathrm{OsO}_{4}$ overnight at $4^{\circ} \mathrm{C}$. After washing in phosphate buffer, the samples were dehydrated through a series of ethanol solutions, then infiltrated with a graded series of epoxy resin in epoxy propane, and embedded in Epon 812 resin. Thin sections were stained in $1 \%$ uranyl acetate, followed by lead citrate solution, and viewed with a transmission electron microscope (HITACHI H-7650, Hitachi, Tokyo, Japan).

\section{High-performance Liquid Chromatography (HPLC) Analysis of Monosaccharide Content}

Glucose, fructose, and sucrose were quantified using the HPLCrefractive index (HPLC-RI) system. Briefly, the frozen samples in liquid nitrogen were ground into a powder, and $100 \mathrm{mg}$ of this sample was dissolved in $0.7 \mathrm{ml}$ of $80 \%$ ethanol to extract the sugars. The sample was thoroughly vortexed and incubated for $2 \mathrm{~h}$ at $70^{\circ} \mathrm{C}$. Aliquots of $0.7 \mathrm{ml}$ of HPLC-grade water and $0.7 \mathrm{ml}$ chloroform were added to the sample. After shaking the mixtures several times, they were centrifuged at $12,000 \mathrm{~g}$ for $10 \mathrm{~min}$. Then, $0.7 \mathrm{ml}$ of the aqueous supernatant was transferred into $1.5 \mathrm{ml}$ Eppendorf tubes and $0.7 \mathrm{ml}$ of chloroform was added. The samples were vortexed for 2-3 min. After centrifugation at $12,000 \mathrm{~g}$ for $10 \mathrm{~min}, 0.5 \mathrm{ml}$ of the supernatant was transferred to a glass tube for HPLC analysis of each sugar component. The sugar-separation method used was that described by the manufacturer but with slight modifications; the HPLC column (ZORBAX carbohydrate column; $4.6 \times 150 \mathrm{~mm}, 5 \mu \mathrm{m}$ ) of Agilent technologies with a differential refraction detector was used. The mobile phase consisted of $75 \%$ acetonitrile with a flow rate of $0.8 \mathrm{ml} / \mathrm{min}$; the temperature of the column was maintained at $35^{\circ} \mathrm{C}$. The sugars were identified based on the retention time of the standards, and sample concentrations were calculated from the external standard curve.

\section{Preparation of Digital Gene Expression Libraries and Sequencing}

The harvested samples from six petri dishes (30-40 tissue clusters/Petri dish) of SEs, FFEC, or OFEC were frozen in liquid nitrogen for homogeneity and held at $-80^{\circ} \mathrm{C}$ prior to transporting to the Beijing Genome Institute (BGI, Shenzhen,
China) for RNA extraction. Total RNA extraction, mRNA purification, cDNA synthesis, and RNA-seq library construction were done as described in a previous study (Liu et al., 2014). The Illumina Cluster Station and Illumina HiSeq 2000 System (Illumina, Inc., CA, USA) was used to perform sequencing with the method of sequencing by synthesis, where each tunnel generated millions of raw reads with a sequencing length of $49 \mathrm{bp}$.

\section{Annotation of Clean Tags and Data Normalization for Gene Expression Level}

Raw sequences were transformed into clean tags through removing adaptor sequence, low-quality sequences [tags with unknown sequences ("N")], empty reads (sequence with only adaptor sequences but no tags), too-long or too-short tags, and tags with a copy number of one (probably a sequencing error). For annotation, all tags were mapped to the reference database (http://www.cassavabase.org, Yang et al., 2011; Prochnik et al., 2012). Clean tags mapped to reference sequences from multiple genes were filtered, and the remaining clean tags were designed as unambiguous tags. For gene expression analysis, the number of unambiguous clean tags for each gene was calculated and then normalized to the number of transcripts per million tags.

\section{Analysis of DEGs}

A rigorous algorithm was developed to identify DEGs among SE, FFEC, and OFEC samples, according to the method described in previous studies (Audic and Claverie, 1997; Liu et al., 2014). The false discovery rate (FDR) was used to determine the threshold of $P$-value in multiple tests and analyses. "FDR $\leq 0.001$ and the absolute value of $\log _{2}$ (sample 1 /sample 2 ) $\geq 1$ " was used as the threshold to judge the significance of gene expression difference (Benjamini and Yekutieli, 2001).

\section{GO Functional Enrichment Analysis and Pathway Enrichment Analysis}

The GO enrichment analysis based on the Gene Ontology database (http://www.geneontology.org) was used to identify the significantly enriched GO terms in DEGs as described in a previous study (Liu et al., 2014). The GO terms with Bonferronicorrected $P \leq 0.05$ were significantly enriched in DEGs. The pathway enrichment analysis based on the Kyoto Encyclopedia of Genes and Genomes (http://www.genome.jp/kegg/) was used to identify significantly enriched pathways in DEGs as described in a previous study (Liu et al., 2014). FDR-corrected Q-value was used for determining the threshold of $P$-value in multiple tests and analysis (Benjamini and Yekutieli, 2001). Pathways with $Q \leq 0.05$ were significantly enriched in DEGs.

\section{Real-time Reverse Transcription-Polymerase Chain Reaction (qRT-PCR) Analysis}

To confirm the results of the DEG analyses, the expression of 32 responsive genes was validated by qRT-PCR with RNA samples extracted with a Plant RNA Reagent (Cat.No.12322-02; Invitrogen, Shanghai, China), according to the manufacturer's protocol. The RNA quality was determined by running 
an agarose gel with ethidium bromide staining. Reverse transcription was performed according to the manufacturer's protocol (Code: TRT-101; TOYOBO, Shanghai, China). Each cDNA sample was diluted two times in sterile $\mathrm{ddH}_{2} \mathrm{O}$, and $1 \mu l$ of this dilution was used as a template for the real-time RT-PCR. Specific primers were designed with Primer-BLAST (http://www.ncbi.nlm.nih.gov/tools/primer-blast) to obtain a $T_{\mathrm{m}}$ of $60^{\circ} \mathrm{C}$ and an amplicon length between 70 and $200 \mathrm{bp}$. The real-time RT-PCR reactions were performed in a $20 \mu \mathrm{l}$ volume containing $10 \mu \mathrm{l}$ of $2 \times$ SYBR Green Master Mix (Code: QPK201, TOYOBO), approximately $50 \mathrm{ng} \mathrm{cDNA}$, and $400 \mathrm{nM}$ of forward and reverse primers in a Bio-Rad CFX96 thermocycler. The amplification conditions were as follows: $95^{\circ} \mathrm{C}$ for $1 \mathrm{~min}$, followed by $40-50$ cycles of $95^{\circ} \mathrm{C}$ for $15 \mathrm{~s}, 60^{\circ} \mathrm{C}$ for $20 \mathrm{~s}$, and $72^{\circ} \mathrm{C}$ for $20 \mathrm{~s}$. A melting curve $\left(65^{\circ} \mathrm{C}-95^{\circ} \mathrm{C}\right.$ with a heating rate of $0.05^{\circ} \mathrm{C} / \mathrm{s}$ and a continuous fluorescence measurement) was run after the PCR cycles. Beta-actin was used as the internal control. All the samples were measured in triplicate, and the experiments were performed on three biological replicates. The comparative $C_{t}$ method was used to calculate the relative gene expression level across the samples. The relative expression level of each gene in one sample $\left(\Delta C_{t}\right)$ was calculated as follows: $C_{t}$ (target gene) $-C_{t}$ (beta-actin). The relative expression of each gene in two different samples $\left(\Delta \Delta C_{t}\right)$ was calculated as follows: $\Delta C_{t}$ (sample 1) $-\Delta C_{t}$ (sample 2).

\section{HPLC Estimation of Global Methylation Rates}

A modified cetyltrimethylammonium bromide (CTAB) method was used for genomic DNA extraction (Soni and Murray, 1994). Purified DNA ( $100 \mu \mathrm{l}$, about $3 \mu \mathrm{g})$ was hydrolyzed into nucleosides for $1 \mathrm{~h}$ at $95^{\circ} \mathrm{C}$ by adding $50 \mu \mathrm{l} 70 \%$ perchloric acid, and the $\mathrm{pH}$ was adjusted to $3-5$ with $5 \mathrm{M} \mathrm{KOH}$ (about $100 \mu \mathrm{l}$ ); then the samples were centrifuged at $12,000 \mathrm{rpm}$ for $10 \mathrm{~min}$. The supernatant was transferred to a new tube and analyzed using an HPLC 1260 system. The HPLC column (ZORBAX carbohydrate column; $4.6 \times 150 \mathrm{~mm}, 5 \mu \mathrm{m}$ ) of Agilent technologies with a UV detector was used. The detection wavelength was fixed to $285 \mathrm{~nm}$. The mobile phase consisted of $75 \%$ acetonitrile with a flow rate of $0.8 \mathrm{ml} / \mathrm{min}$, and the temperature of the column was maintained at $35^{\circ} \mathrm{C}$. Cytosine (C3506, Sigma, MO, USA) and 5-methylcytosine hydrochloride (M6751, Sigma) were used as standards. The cytosine and 5-methylcytosine were identified based on the retention time of the standards, and sample concentrations were calculated from the external standard curve. The global methylation rate (GMR) was calculated using the following formula: $\mathrm{GMR}=(5 \mathrm{mC}) /[(\mathrm{C})+(5 \mathrm{mC})] \times 100 \%$. All analyses were repeated three times, and the mean \pm standard error (SE) was calculated.

\section{Flow Cytometry Analysis}

The harvested samples of $0.3 \mathrm{~g}$ were gently chopped with a razor blade in a petri dish containing $1.5 \mathrm{ml}$ modified Galbraith's extraction buffer (Galbraith et al., 1983) supplemented with $5 \mathrm{mM}$ sodium metabisulfite and $0.5 \%$ mercaptoethanol. The chopped samples were then filtered through a $40 \mu \mathrm{m}$ mesh, then a $7.5 \mu \mathrm{l}$ DAPI buffer (final concentration $5 \mu \mathrm{g} / \mathrm{ml}$ ) was added to it and kept in dark for $5 \mathrm{~min}$. The isolated nuclei were analyzed at a concentration of 150,000 cells per sample using a MoFlo XDP flow cytometer. Obtained histograms were evaluated using the Summit 5.2 software (Beckman Coulter, CA, USA, http://www. beckmancoulter.com). Results from two biological replicates, each with duplicated samples were analyzed. The leaves from TMS60444 in vitro were treated as control with the fluorescence peak at channel position $1.7 \times 10^{4}$ (FL6-Log_Height). The Sphase fraction (SPF) was calculated using the following formula: $\mathrm{SPF}=\mathrm{S} /\left(\mathrm{G}_{0} / \mathrm{G}_{1}+\mathrm{S}+\mathrm{G}_{2} / \mathrm{M}\right) \times 100 \%$. The proliferation index (PI) was calculated using the following formula: $\mathrm{PI}=(\mathrm{S}+$ $\left.\mathrm{G}_{2} / \mathrm{M}\right) /\left(\mathrm{G}_{0} / \mathrm{G}_{1}+\mathrm{S}+\mathrm{G}_{2} / \mathrm{M}\right) \times 100 \%$.

\section{Results}

\section{Cytological and Physiological Changes of SEs, FFEC, and OFEC}

The SE clusters usually contained mixed types of SEs with global, heart, torpedo, and cotyledon stages, which were ready for further multiplication on a cassava induction medium (CIM) containing $50 \mu \mathrm{M}$ picloram or to be used for FFEC induction on a GD medium under continuous darkness (Figure 1). The SE cells were well-arranged with dense cytoplasm and absence of DNA fragmentation as indicated by TUNEL- and DAPI-stained paraffin sections. The FFEC was a light yellow, highly friable callus with numerous spherical embryogenic units and sparse cytoplasm with less well-arranged nuclei. The OFEC was pale yellow and less well-organized having sponge-like cell structure with few detectable nuclei (Figure 1). OFEC showed lower plant regeneration capacity and usually gave abnormal phenotype, such as dwarf, yellow, and/or slim, or twisted leaves (data not shown).

Under a transmission electron microscope, the isodiametric SE cells were detected and their cell cytoplasm was distributed uniformly with a clear cell wall boundary (Figure 2A). Both FFEC and OFEC cells showed irregular shapes with very thin cell walls and contained large vacuoles, but the FFEC cells showed denser cytoplasm compared with the OFEC cells. Two types of cells were identified in FFEC, one with small vacuolar vesicles and another with a larger vacuole as in the OFEC cells. Some of the OFEC cells contained debris and were less organized (Figures 2G,M). A number of starch granules were observed inside the SE cells with several starch granules in one plastid (Figure 2B). No starch granule was found in the FFEC and OFEC cells (Figures $\mathbf{2 H}, \mathbf{N}$ ). When checking the subcellular organelles, the SEs detected regular Golgi body, mitochondria, and rough endoplasmic reticulum (RER). These organelles of FFEC and OFEC had irregular shapes and were consistent with higher dense RER and more binding ribosomes (Figures 2C-E,I-K,O-Q). Free ribosomes became enriched in FFEC and OFEC, which indicated active protein synthesis (Figures 2F,L,R).

The analysis of sugars by HPLC indicated that the contents of fructose and glucose increased significantly but the sucrose content decreased dramatically in OFEC (Figure 3), indicating that the status of sucrose homeostasis is changed during the long-term subculturing process. No significant difference of fructose and glucose contents was found between SEs and FFEC. 


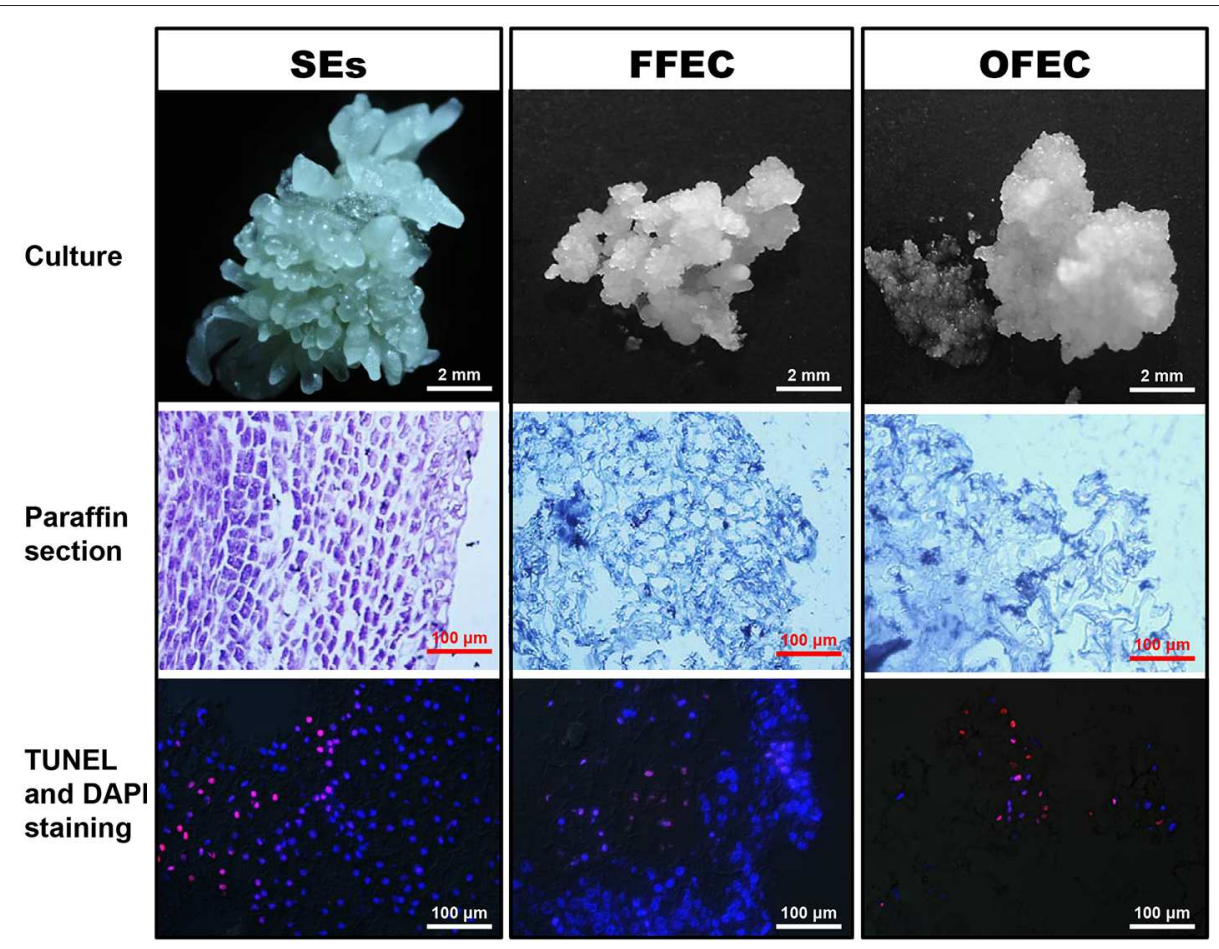

FIGURE 1 | SEs, FFEC, and OFEC of cassava and observation of their TUNEL- and DAPI-stained paraffin sections.

\section{Solexa Sequencing and Annotation Analysis Revealed Dynamic Gene Expression among SEs, FFEC and OFEC}

Using the Solexa sequencing technology, the genome-wide gene expression change in SEs, FFEC, and OFEC was analyzed. The copy number distribution of the clean tags and the saturation evaluation of different expressions validated the sequencing quality. The distribution of total tags and distinct tags over different tag abundance categories showed similar patterns for three DEG libraries, suggesting there was no bias in the construction of the libraries from SEs, FFEC, and OFEC (data not shown). To explore the DEGs in the three samples, three DEG libraries were mapped to the reference database of cassavaexpressed sequence tags, which generated about 4.90 million raw tags for each sample (Supplementary Table 1). After the removal of the low-quality reads, the total number of tags per library ranged from 4.67 to 4.70 million and the number of distinct tags ranged from 173,690 to 203,119 . About $34.81-46.33 \%$ distinct tags in all clean tags were mapped to reference genes, and $19,800,19,840$, and 19,366 unambiguous tag-mapped genes were identified in SE, FFEC, and OFEC samples, respectively (Supplementary Table 1).

Using the criteria of FDR $<0.001$ and a two-fold change in expression, 6871 DEGs were identified in the three samples (Figure 4). Among the DEGs, 2306, 1769, and 1271 genes were upregulated and 2683, 2362, and 1153 were downregulated by analyzing OFEC/SEs, FFEC/SEs, and OFEC/FFEC, respectively. In three comparisons, 127 and 183 genes were upregulated and downregulated, respectively (Figure 4). The DEGs were more in
OFEC/SEs and FFEC/SEs than in OFEC/FFEC, implying that FFEC, and OFEC were closer in genetic status compared with SEs, which was consistent with the biological process as well as cytological observations.

To validate the Solexa sequencing data, the qRT-PCR analysis was performed on 18 selected DEGs belonging to different functional categories or pathways (Table 1). There were 94.44, 72.22 , and $100.00 \%$ consistency between the results measured by real-time RT-PCR and RNA-seq among FFEC/SEs, OFEC/FFEC, and OFEC/SEs, respectively.

\section{GO Clustering of DEGs and Clustering of Significant Pathways Involved}

The GO terms of "cellular process," "molecular function," and "biological process" were significantly enriched among SEs, FFEC, and OFEC (Figure 5). Of them, the categories including "cell periphery," "external encapsulating structure," "oxidoreductase activity," and "response to chemical stimulus" were significantly regulated in FFEC (Supplementary Table 2). In OFEC, the main categories contained terms for "cell cycle related," "cytoskeleton related," "chromatin," and "nucleotide related" (Figure 5). According to the threshold of $P<0.05$ and $Q<0.05,14$ significant pathways were identified (Figure 6A). In FFEC, the main pathways included were "plant hormone signal transduction" (ko04075), "glycolysis/gluconeogenesis" (ko00010), and "alanine, aspartate, and glutamate metabolism" (ko00250). Different pathways involved in OFEC are "base excision repair" (ko03410), "DNA replication" (ko03030), "nucleotide excision repair" (ko3420), and "mismatch repair" 


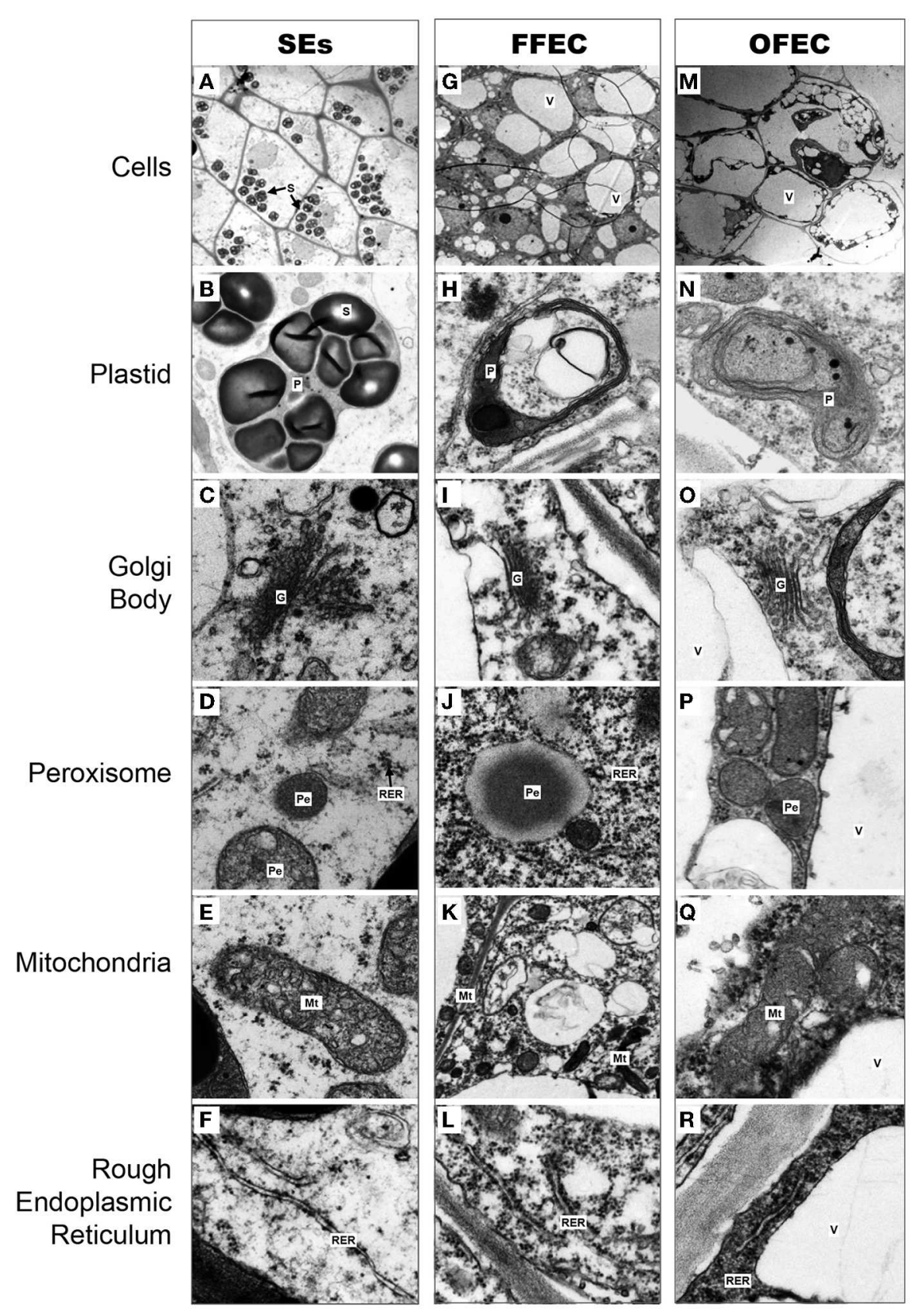

FIGURE 2 | Cytological observations of cells in SEs (A-F), FFEC (G-L), and OFEC (M-R) of cassava by TEM. G, Golgi body; Mt, mitochondria; P, plastid; Pe, peroxisome; RER, rough endoplasmic reticulum; S, starch granule; V, vacuole.

(ko3430), all of which were related to the DNA synthesis and repair process (Figure 6A).

\section{Changes during the FEC Formation Process (FFEC/SEs)}

The "plant hormone signal transduction" (ko04075) pathway was significantly enriched (Figure 6B); in this pathway, a number of growth-associated processes were activated, including tryptophan metabolism (auxin), zeatin biosynthesis (cytokinine), diterpenoid biosynthesis (gibberellin), cysteine, and methionine metabolism (ethylene), and brassinosteroid biosynthesis (brassinosteroid) (Supplementary Table 3). These processes played a crucial role in the FEC formation process for regulating elongation and cell division. In the tryptophan metabolism (auxin) pathway, most of the genes involved in this metabolism were downregulated except the auxininduced protein $\mathrm{X} 10 \mathrm{~A}$ and the auxin-responsive protein IAA16. 


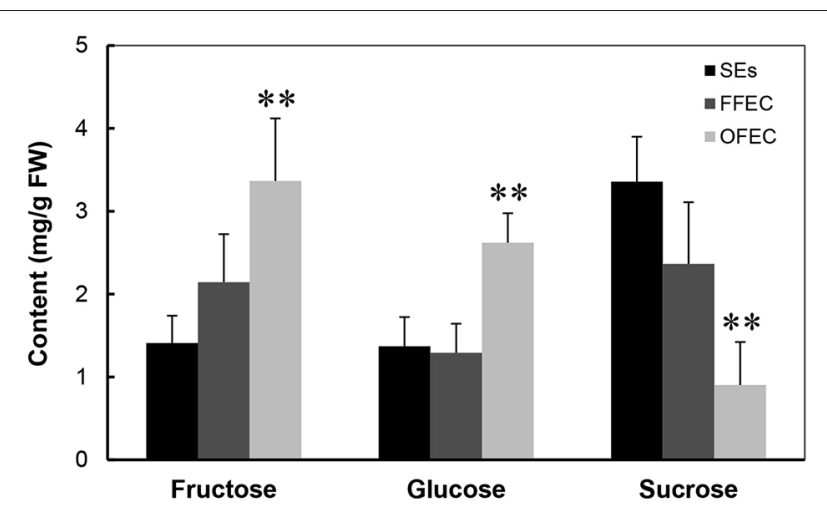

FIGURE 3 | Contents of fructose, glucose, and sucrose in SEs, FFEC, and OFEC. The double asterisks indicate a statistically significant difference at $P<0.05$ by Student's $t$-test. The mean values are calculated from three biological replicates, and the error bars represent the standard error of the mean (SEM).

In the diterpenoid biosynthesis (gibberellin) process, the genes of GA including cyclin D, glucan endo-1,3-betaglucosidase precursor, protein kinase, and protein phosphatase $2 c$ play functions in the cell reconstruction of structure and endomaterials. In this study, gibberellin receptor GID1, GRAS family transcription factor (TF), and ubiquitin-protein ligase were upregulated, but DELLA protein was downregulated (Supplementary Table 3). The DELLA protein was degraded by ubiquitin-mediated gibberellin receptor GID1 that combined with GA; therefore, the genes related with GA were induced, which could lead to cell reconstruction.

In the GO terms of "cellular process," the largest and second categories of "cell periphery" and "external encapsulating structure," accounting for 7.80 and $6.70 \%$ of the total GOs, respectively, might be the most important components related to the FEC formation. Since all genes in the category of "external encapsulating structure" were overlapping with genes in the GO terms of "cell periphery," the two categories were combined for analysis and discussion (Supplementary Table 2). Among the 57 genes significantly changed at FFEC/SEs, 42 genes were downregulated and 15 genes upregulated. Many genes that loosen the cell wall structure were detected, including alpha-expansin 11 precursor, xyloglucan endotransglucosylase/hydrolase protein 22 precursor (XTH), pectin acetylesterase, and so on. Many genes involved in the polysaccharide hydrolase of cell wall were observed, such as alpha-galactosidase, alpha-glucosidase, beta-galactosidase, glucan endo-1,3-beta-glucosidase precursor, xylan 1,4-betaxylosidase, hydrolyzing O-glycosyl compounds, periplasmic beta-glucosidase precursor, acid beta-fructofuranosidase precursor, triosephosphate isomerase, and so on. For example, pectinesterase precursors and glucan endo-1,3-beta-glucosidase precursors were downregulated dramatically, and pectin acetylesterase (cassava4.1_032451m|pacid:17979110) and alphagalactosidase/alpha- $N$-acetylgalactosaminidase (cassava4.1_ 011258m|pacid:17973258) were upregulated.

The genes of protein hydrolysis, including $26 \mathrm{~S}$ protease regulatory subunit $\mathrm{S} 10 \mathrm{~b}$, aspartic proteinase nepenthesin-1
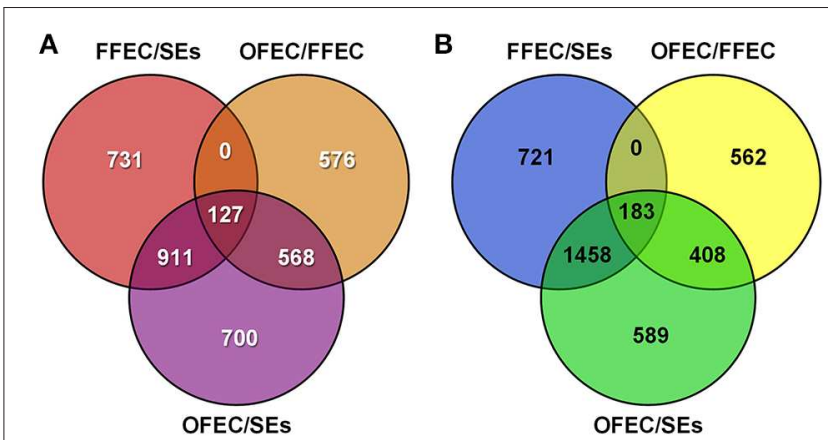

FIGURE 4 | The Venn diagram depicts the (A) upregulated and (B) downregulated genes in paired comparisons. FFEC/SEs, fresh friable embryogenic callus/somatic embryos; OFEC/FFEC, old friable embryogenic callus/fresh friable embryogenic callus; OFEC/SEs, old friable embryogenic callus/somatic embryos.

precursor, and other genes were all significantly downregulated. The factors responsible for external stimulus betaine-aldehyde dehydrogenase, multicopper oxidase, and leucine-rich repeat in FFEC had also downregulated expression compared with that in SEs. The genes, for example, similar to TUBG1 (gamma-tubulin), involved in cytoskeleton construction were downregulated while fimbrin and tubulin alpha- 8 chain were significantly upregulated in FECs compared to SEs.

Furthermore, other genes containing a wide range of biological functions were detected, including protein kinase (e.g., serine-threonine protein kinase), heat shock proteins (e.g., heat shock protein), protein synthesis (e.g., 40S ribosomal protein S27), protein folding (e.g., calnexin), lipid metabolism (e.g., acid phosphatase one precursor), nucleotide metabolism (e.g., amidophosphoribosyltransferase), and auxin-responsive protein (e.g., GAST1 protein precursor). Moreover, the transcription factors (TFs) differentially expressed during the culture process were also monitored (Supplementary Table 6). Significant upregulation of TFs (e.g., AP2/ERF TF, MADS-box TF 2, R2R3-MYB TF, BIM1 TF, and WRKY TF) was detected in FFEC/SEs ( $\log _{2}$ ratio $>5$ ) but more down-regulated TFs were also found during the process ( $\log _{2}$ ratio $\left.<-5\right)$. Interestingly, most of these TFs down-regulated in FFEC/SEs were up-regulation in OFEC/FFEC, indicating the regulation of FEC induction is different from the FEC subculture process.

\section{Rapid Cell Cycle and Repair Mechanism during the FEC Continuous Subculture Process (OFEC/FFEC)}

Many significantly expressed pathways, including "base excision repair," "DNA replication," "nucleotide excision repair," and "match repair," involved in DNA replication or repair, were found during the FEC continuous subculture process (OFEC/FFEC) (Supplementary Table 4). In these pathways, many important genes related to the DNA damage-induction repair process, such as replication factor $\mathrm{C}$ (RFC), proliferating cell nuclear antigen (PCNA), and replication protein A (RPA), were also significantly upregulated. 
TABLE 1 | Validation of selected gene expression by real-time RT-PCR.

\begin{tabular}{|c|c|c|c|c|c|c|c|}
\hline \multirow[t]{2}{*}{ Genes } & \multirow[t]{2}{*}{ Description } & \multicolumn{3}{|c|}{ Solexa } & \multicolumn{3}{|c|}{ qRT-PCR } \\
\hline & & $\begin{array}{c}\text { FFEC/ } \\
\text { SEs }\end{array}$ & $\begin{array}{l}\text { OFEC/ } \\
\text { FFEC }\end{array}$ & $\begin{array}{c}\text { OFEC/ } \\
\text { SES }\end{array}$ & $\begin{array}{c}\text { FFEC } \\
\text { SEs }\end{array}$ & $\begin{array}{l}\text { OFEC/ } \\
\text { FFEC }\end{array}$ & $\begin{array}{c}\text { OFEC/ } \\
\text { SEs }\end{array}$ \\
\hline Cassava4.1_000881m & Histidine kinase cytokinin receptor, Mrna (CRE) & -3.53 & 1.19 & -2.34 & -3.67 & 2.76 & -0.91 \\
\hline Cassava4.1_012131m & $\mathrm{NAD}^{+}$ & 4.14 & -0.58 & 3.56 & 4.94 & 0.87 & 5.81 \\
\hline Cassava4.1_004367m & Acetyl-CoA synthetase & 3.32 & -0.11 & 3.21 & 0.97 & 0.90 & 1.87 \\
\hline Cassava4.1_019292m & Auxin-responsive protein IAA & -10.63 & - & -10.63 & -1.81 & -0.32 & -2.13 \\
\hline Cassava4.1_003815m & Auxin-responsive GH3 gene family & -5.74 & -1.41 & -7.16 & -1.46 & -0.86 & -2.32 \\
\hline Cassava4.1_019233m & SAUR family protein & -10.42 & 7.71 & -2.71 & -2.47 & 1.74 & -0.73 \\
\hline Cassava4.1_004821m & Pectinesterase-3 precursor & -8.12 & 5.39 & -2.73 & -4.21 & 2.32 & -1.89 \\
\hline Cassava4.1_006815m & Predicted: similar to TUBG1 (gamma-tubulin) & -8.23 & 7.85 & -0.38 & -2.62 & 2.40 & -0.22 \\
\hline Cassava4.1_001933m & Kinesin & -7.00 & 8.40 & 1.40 & -2.23 & 2.25 & 0.02 \\
\hline Cassava4.1_008560m & Cell division protein FtsZ & -0.58 & 1.39 & 0.80 & 0.38 & 1.02 & 1.40 \\
\hline Cassava4.1_010144m & Cyclin A & -6.74 & 8.40 & 1.66 & -2.27 & 5.14 & 2.87 \\
\hline Cassava4.1_005111m & GLN phosphoribosyl pyrophosphate amidotransferase 2 & 1.19 & 0.31 & 1.51 & 1.42 & 0.77 & 2.18 \\
\hline Cassava4.1_009073m & Phosphoribosyltransferase family protein & 1.58 & 0.24 & 1.82 & 0.40 & 0.69 & 1.09 \\
\hline Cassava4.1_010597m & Glutamine synthase clone R1 & 2.28 & -0.01 & 2.27 & 2.59 & 0.40 & 2.99 \\
\hline Cassava4.1_006179m & Glutamate decarboxylase & -3.23 & 1.50 & -1.73 & -4.91 & 2.84 & -2.07 \\
\hline Cassava4.1_004336m & Phosphoglucomutase/phosphomannomutase family protein & 1.32 & 0.12 & 1.43 & 0.47 & 0.77 & 1.24 \\
\hline Cassava4.1_006657m & UDP-glucose 6-dehydrogenase family protein & -1.90 & -0.50 & -2.40 & -1.81 & 0.87 & -0.93 \\
\hline Cassava4.1_031387m & Xylan 1,4-beta-xylosidase & -8.23 & 5.39 & -2.84 & -2.83 & 1.98 & -0.85 \\
\hline
\end{tabular}

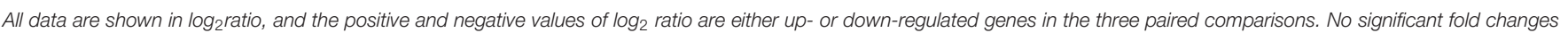
are indicated as "-." Values of real-time RT-PCR analysis shown in bold font indicate inconsistent data compared with Solexa analysis.

In the GO terms of "molecular function," the "cell cyclerelated terms" were identified. Since many genes in the category of "cell cycle" overlapped with genes in the GO terms of "cell cycle process" and "M phase," these categories were combined for analysis and discussion. All genes in this term, including cyclin B, cdc6, kinesin, CDK, smg-7, cyclin A, and so on, were significantly upregulated at OFEC/FFEC, except for cop9 complex subunit (Figure 7A, Supplementary Table 5).

Among the significant upregulated TF $\left(\log _{2}\right.$ ratio $>5$ ) in OFEC/FFEC, one third of TFs showed upregulation in FFEC/SEs, including ethylene-responsive TF, R2R3-MYB TF, MADS-box TF 3 and WRKY TFs; The rest of them were considerably down-regulated in FFEC/SEs $\left(\log _{2}\right.$ ratio $<-5$ ) (Supplementary Table 6). Some TFs might be related to the cell cycle progress, such as TF E2F and TF DP-1. Overall, the changes of TF expression showed different scenarios between OFEC/FFEC and FFEC/SEs.

\section{Methylation Levels Reduced in OFEC}

DNA methylation dysfunctions can lead to developmental abnormalities in animals and plants (Finnegan et al., 2000). To evaluate the methylation levels in SEs, FEC, and OFEC and possible causes in high somaclonal variation of regenerated cassava plants from OFEC, the global methylation ratios were evaluated by the HPLC analysis. The ratio of methylation had no significant changes between SEs and FFEC, both were about 50\%. However, the ratio of methylation in OFEC decreased significantly, which was almost $27 \%$ (Figure 7B).

\section{Unchanged Ploidy Level in SEs, FFEC, and OFEC}

Flow cytometry analysis was performed to examine the nuclear ploidy during FEC formation and continuous culturing process. The DNA contents of SEs, FFEC, and OFEC analyzed by flow cytometry were similar to that of the leaves, which indicated that the ploidy of SEs, FFEC, and OFEC had no difference (Supplementary Figures 1A-D). Nevertheless, the OFEC cells contained more 4C cells (26.5\% of total 4C and 2C cells) compared with SE and FFEC cells. The FFEC cells only had $17.6 \% 4 \mathrm{C}$ cells (Figure 8A). The OFEC cells contained the highest ratios of SPF and PI, 15.57, and 37.92\%, respectively, compared to the SE and FFEC cells (Figure 8B). Since most of cell cycle-related gene were also up-regulated (Figure 7A, Supplementary Table 5), these data indicate the OFEC cells possessed stronger proliferation ability during the subculture process.

\section{Discussion}

Callus induction is a complicated biological process of cell differentiation and dedifferentiation regulated by genetic and epigenetic mechanisms (Ikeuchi et al., 2013). Despite the importance of FEC as a key tool for cassava genetic engineering (Liu et al., 2011), less studies have been made to understand the mechanisms underlying the FEC induction and longterm subculture. In this study, transcriptomic, structural, and physiological changes were analyzed during the FEC induction and subculture process. The activation of hormone signal transduction pathway played a key role in inducing 
A

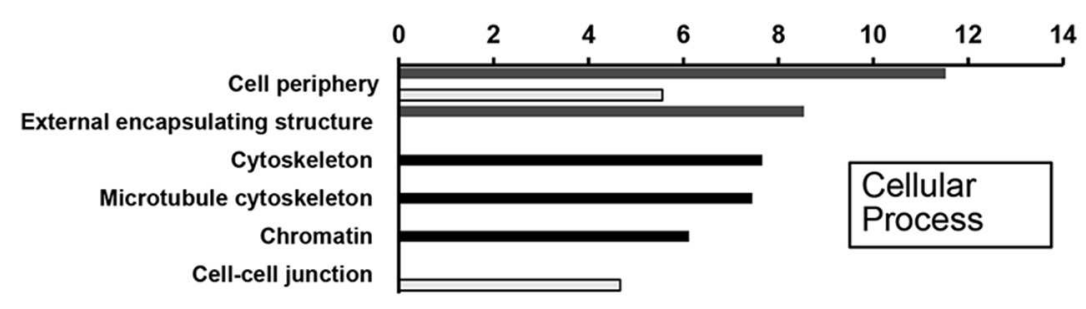

B

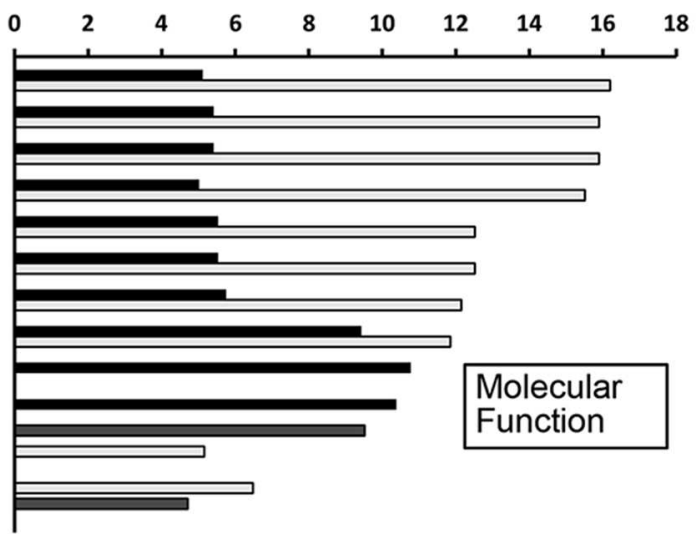

Oxidoreductase activity, acting on the $\mathrm{CH}-\mathrm{CH}$ group of donors

Adenyl ribonucleotide binding

Purine nucleoside binding

Adenyl nucleotide binding

Nucleoside binding

Ribonucleotide binding

Purine ribonucleotide binding

Purine nucleotide binding

Binding

Motor activity

Microtubule motor activity

Oxidoreductase activity

Nucleotide binding

E

C

Response to stimulus

M phase

Cell cycle

Cell cycle process

Microtubule-based process

Response to chemical stimulus

Hormone-mediated signaling pathway

Cellular response to endogenous stimulus

Cellular response to hormone stimulus

Signaling

Cell cycle phase

Response to endogenous stimulus

Cellular response to chemical stimulus

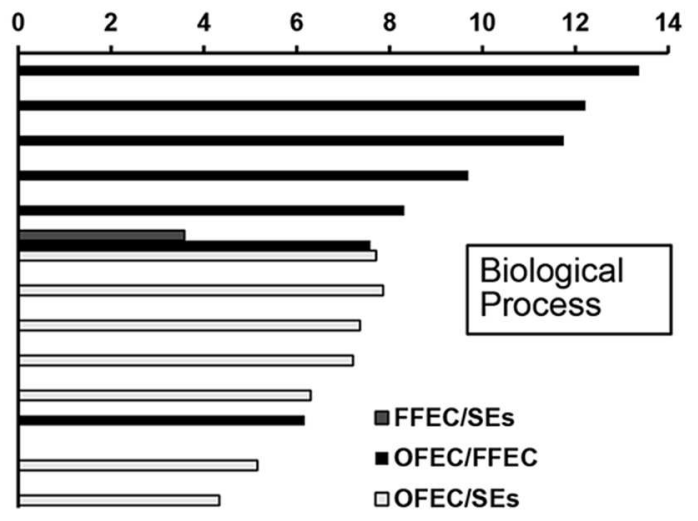

FIGURE 5 | Significantly enriched GO terms of "cellular process" (A), "molecular function" (B), and "biological process" (C) by comparing SEs, FFEC, and OFEC $(\boldsymbol{P} \leq \mathbf{0 . 0 5})$. The " $y$ " axis represented enriched GO terms among three samples. The " $x$ " axis represented the $P$-value $\left(-\log _{2} P\right)$.

the expression of genes participating in cell reconstruction for the transformation from SE cells to FFEC. During the FEC subculture process, the cell cycles were accelerated by upregulating the cell cycle-related genes accompanying the dramatic reduction of the methylation level and changed expression of TFs. The gene repair mechanism was also enhanced. The acceleration of cell division in FEC potentially resulted in more somaclonal variations during FEC subculture. Hence, the study increased the understanding of genetic and physiological changes during the FEC formation and subculture, providing cues to develop a robust protocol for farmer-preferred or recalcitrant cultivars.

The transition from SEs to FFEC is the key limiting factor in the cassava genetic transformation system. Structural changes, mainly in the cell wall, were proved to be critical for callus formation (Ikeuchi et al., 2013), and loosening of the cell wall was noticed in the isodiametric conjunction of SEs cultured on a GD medium for 2 weeks during the FEC induction process. Much thinner cell wall existed in FFEC and OFEC (Figure 2). The GO terms of the largest and second categories of "cell periphery" and "external encapsulating structure" were enriched in the "cellular component," indicating that FEC formation was associated with cell reconstruction in SEs. Totally 15 genes were significantly upregulated and 42 genes were downregulated during the transition process from SEs to FFEC, including the genes of cell wall formation (Supplementary Table 2). For example, XTHs that mediate cleavage and rejoining of the $\beta(1-4)$-xyloglucans of the primary cell wall seem to achieve regulated wall loosening during turgor-driven expansion by rearranging load-bearing xyloglucan cross-links between cellulose microfibrils (Jan et al., 2004; Saladie 

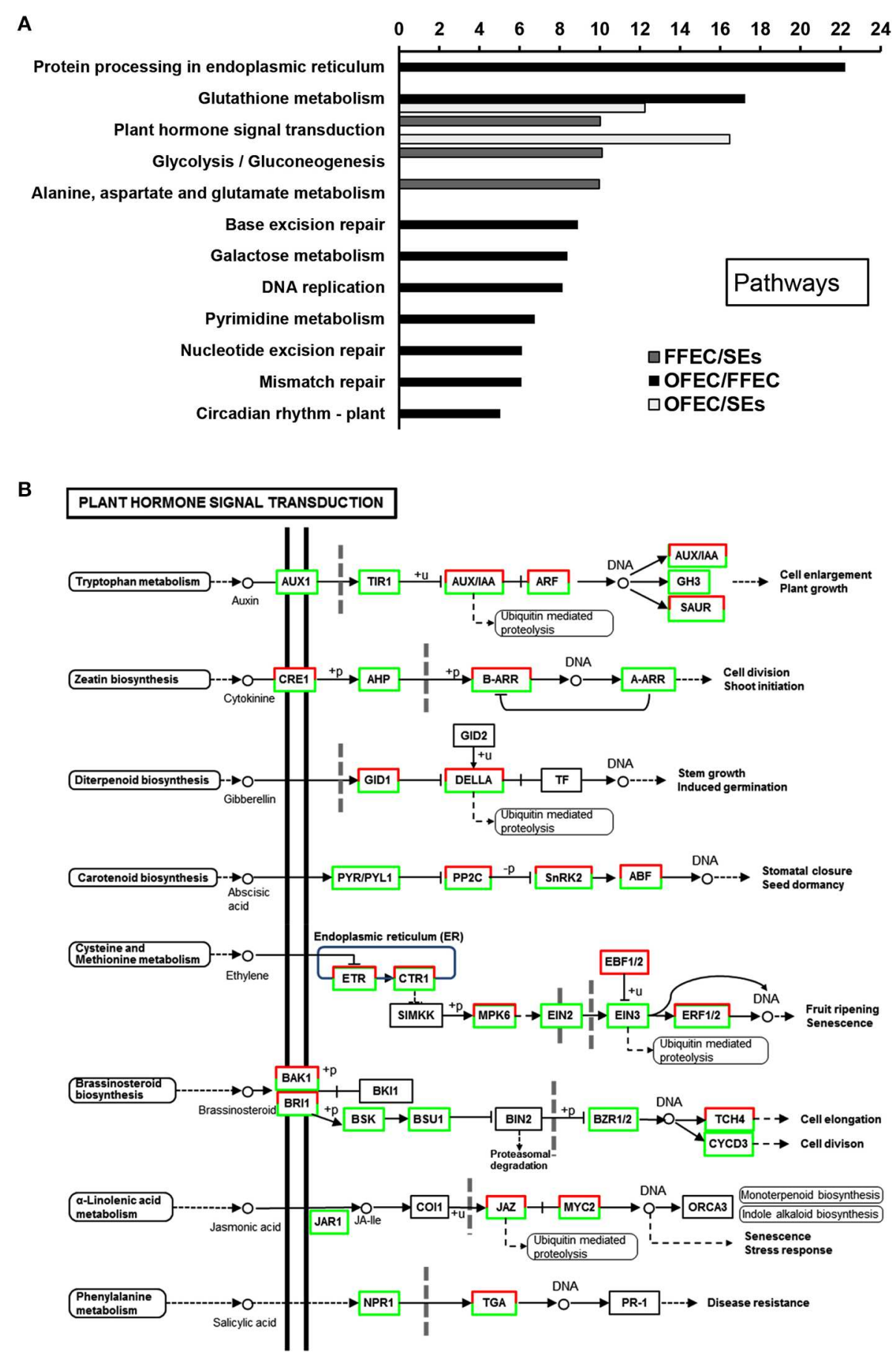

FIGURE 6 | Significantly enriched pathways (A) and changes of plant hormone signal transduction (B) by comparing SEs, FFEC, and OFEC (P < 0.05). The " $y$ " axis represented enriched pathways among the three samples, and the " $x$ " axis represented the $P$-value $\left(-\log _{2} P\right)$.

et al., 2006). Pectin acetylesterase modulates the precise status of pectin acetylation to affect the remodeling and physiochemical properties of the cell wall's polysaccharides, thereby affecting cell extensibility (Gou et al., 2012). Pectinesterase could catalyze the de-esterification of pectin into pectate and methanol, and stiff the cell wall by producing blocks of unesterified carboxyl groups that can interact with calcium ions forming a pectate gel (Micheli, 2001). The transcription of all these genes decreased significantly in FFEC/SEs. The genes such as xylan 1,4-beta-xylosidase, which catalyzed the breakage of glycosidic bond to hydrolyze cell wall into small polymer (Dilokpimol et al., 2011), were upregulated. Indeed, the mechanical damage such as wounding organized 


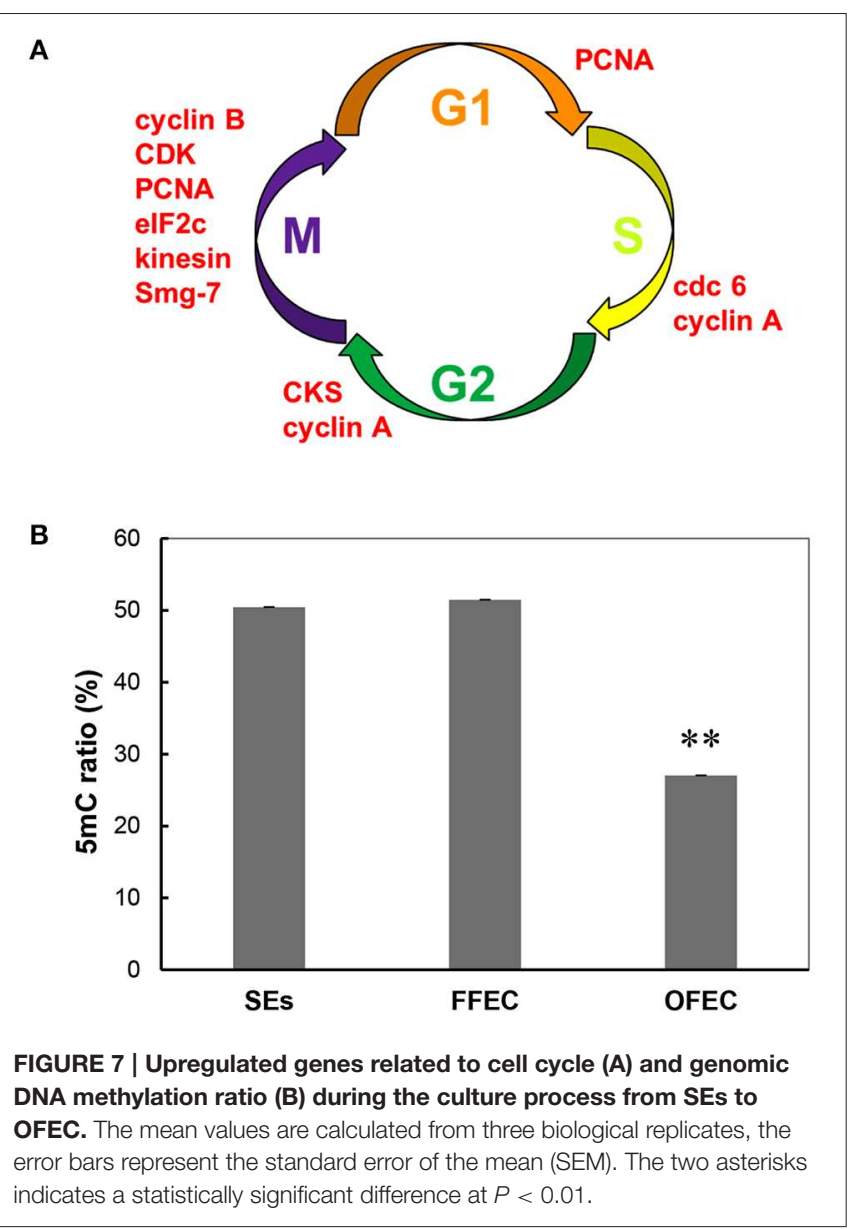

embryogenic structures to encourage FEC production had been reported by a previous study (Taylor et al., 2012). These genes might play a crucial role in the FEC induction process through participating in cell reconstruction.

The hormone signal transduction and cell cycle-related categories were enriched at OFEC/SEs and OFEC/FFEC, respectively. The components in the "plant hormone signal transduction" (ko04075) pathway were activated (Figure 6B), including tryptophan metabolism (auxin), zeatin biosynthesis (cytokinine), diterpenoid biosynthesis (gibberellin), cysteine, and methionine metabolism (ethylene), and brassinosteroid biosynthesis (brassinosteroid), which was consistent with the results of previous research. The pathways of plant hormone signal transduction were enriched during the initiation of embryogenic tissues (Elhiti et al., 2013; Li et al., 2014). But the previous studies indicated that hormonal signaling networks could establish functional links between the regulatory mechanisms of the cell cycle and genes involved in callus formation (Pischke et al., 2006), and the callus-forming capacity in hypocotyls with age may work in concert to altered cytokinin signaling components, cell cycle regulation, and epigenetics (Chen et al., 2012). Dramatic changes of TF expression during FEC subculturing were detected and some TFs are hormone responsive-related (Supplementary Table 6). These data support that the hormone response changed greatly over the long-term
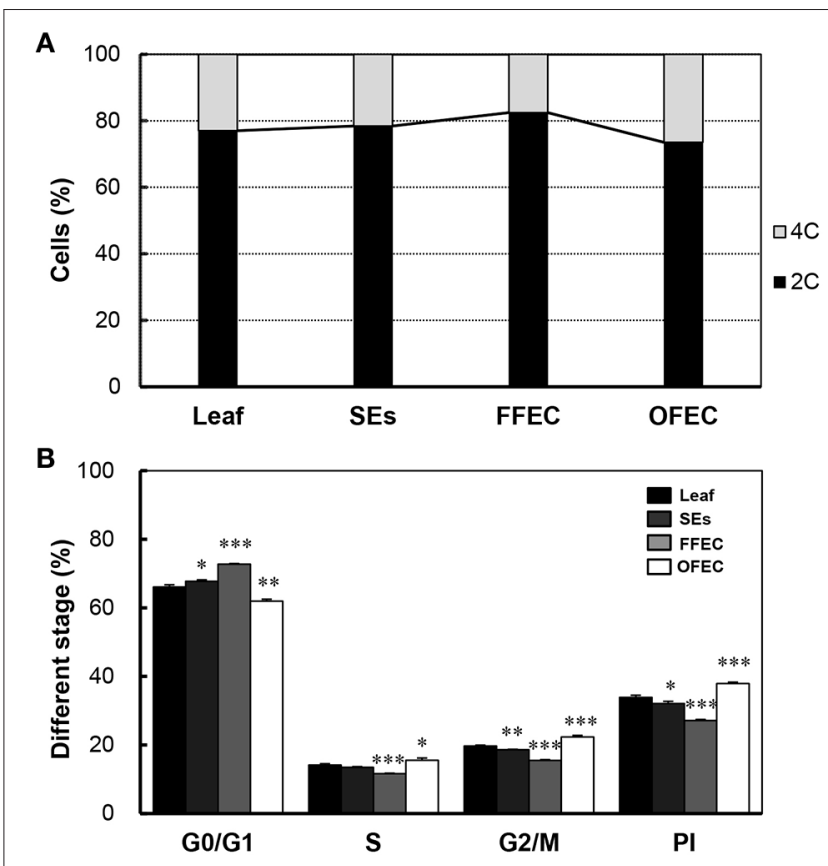

FIGURE 8 | Flow cytometric analysis of leaf, SEs, FFEC, and OFEC. (A) Predominant G1/G0 peak (channel $1.7 \times 10^{4}$ ) of the diploid $(2 n=2 x=36$ ) and their relative ratios of $2 \mathrm{C}$ and $4 \mathrm{C}$ cells. (B) The percentage of cells in $\mathrm{G0} / \mathrm{G} 1, \mathrm{~S}$, and $\mathrm{G} 2 / \mathrm{M}$ phases. Pl indicates the proliferation index, $\mathrm{PI}=(\mathrm{S}+$ $\mathrm{G} 2 / \mathrm{M}) /(\mathrm{GO} / \mathrm{G} 1+\mathrm{S}+\mathrm{G} 2 / \mathrm{M}) \times 100 \%$. The single, double, and triple asterisks indicate a statistically significant difference at $P<0.05, P<0.01$, and

$P<0.001$, respectively. The mean values are calculated from three biological replicates, and the error bars represent the standard error of the mean (SEM).

subculture, leading to dramatic changes in cell status genetically and epigenetically.

Starch granules were only discovered in plastids of SEs (Figure 2B), indicating SEs had different sucrose and starch metabolism from FFEC and OFEC. Increase of fructose and glucose and decrease of sucrose in OFEC indicated its vigorous sugar metabolism during the FEC subculture process. The OFEC cells might consume more energy in the process of cell proliferation due to its rapid cell division. In Valencia sweet orange, histological study of non-embryogenic, and embryogenic callus showed that starch accumulation in amyloplasts of embryogenic cells was obviously increased (Ge et al., 2012). Therefore, it might be necessary to gradually increase the sucrose content from normal 3 to $6 \%$ during FEC subculture to maintain the embryogenic nature of FEC. In fact, the embryogenic suspension established by culturing FEC in the liquid $\mathrm{SH}$ medium contains high sucrose content of 6\% (Zhang and Gruissem, 2004). Additionally, many pathways involving protein processing in ER; glutathione metabolism; and alanine, aspartate, and glutamate metabolism were also changed. Indeed, supplementing additional amino acids, for example, tyrosine, in cassava could enhance FEC induction in a genotype-dependent manner (Nyaboga et al., 2013).

Severe somaclonal variations in regenerated plants were noticed when using cassava FEC system, such as dwarf, yellow, and/or slim, or twisted leaves, even white plants (Raemakers 
et al., 2001; Taylor et al., 2004). The GO terms of "molecular function" at OFEC/FFEC partly explained the appearance of somaclonal variation. Most genes were upregulated except for cop9 complex subunit, including cyclin A, cyclin B, Cdc6, CDK, kinesin, PCNA, eukaryotic translation initiation factor $2 \mathrm{c}$ (eIF 2C), and so on. Apparently, the cell cycles were fastened during the continuous subculture of FEC, which is further manifested by the flow cytometry analysis in which the OFEC cells contained the highest ratios of SPF and PI (Figure 8B). No change of ploidy levels of FEC was observed during subculture. Furthermore, four pathways related with DNA repair and mutation were significantly enriched at OFEC/FFEC, including "base excision repair," "DNA replication," "nucleotide excision repair," and "match repair." The genes participating in DNA repair and replication were significantly upregulated, including RFC, PCNA, and RPA (Singh et al., 2010). Many TFs were identified and showed different expression scenarios among FFEC/SEs, OFEC/FFEC and OFEC/SEs (Supplementary Table 6). Therefore, mutagenesis during the continuous FEC subculture process can occur with the increasing DNA damage and repair.

Epigenetic regulation plays an important role in callus formation by affecting gene expression via chromatin modification including DNA methylation and histone modification (Ikeuchi et al., 2013). The DNA methylation ratio of OFEC almost reduced two-fold compared with the SE and FFEC cells, indicating many genes had different expression profiles in the OFEC cells, including the genes with cell cycles and DNA replication, DNA repair, and unknown function, which might partly lead to the somaclonal variation of the regenerated plants (Rival et al., 2013). Plants with decreased methylation displayed a number of phenotypic and developmental abnormalities, including reduced apical dominance, smaller plant size, altered leaf size, and shape, decreased fertility, and altered flowering time, and so on (Finnegan et al., 2000).

\section{Conclusions}

In summary, the study presented a genome-wide gene expression profiling related to FEC formation and subculture process of TMS60444 cultivar by the use of RNA-seq. The important event

\section{References}

Audic, S., and Claverie, J. M. (1997). The significance of digital gene expression profiles. Genome Res. 7, 986-995.

Awoleye, F., Vanduren, M., Dolezel, J., and Novak, F. J. (1994). NuclearDNA content and in-vitro induced somatic polyploidization cassava (Manihot esculenta Crantz) breeding. Euphytica 76, 195-202. doi: 10.1007/BF00022164

Baba, A. I., Nogueira, F. C. S., Pinheiro, C. B., Brasil, J. N., Jereissati, E. S., Juca, T. L., et al. (2008). Proteome analysis of secondary somatic embryogenesis in cassava (Manihot esculenta). Plant Sci. 175, 717-123. doi: 10.1016/j.plantsci.2008.07.014

Bairu, M. W., Aremu, A. O., and Van Staden, J. (2011). Somaclonal variation in plants: causes and detection methods. Plant Growth Regul. 63, 147-173. doi: 10.1007/s10725-010-9554-x

Beeching, J. R. (2013). Manihot Esculenta (Cassava). eLS. Chichester, UK: John Wiley \& Sons, Ltd. for FEC induction for SEs is the cell reconstruction with the loosening cell wall. Changing the basic medium components, especially the micronutrients, might facilitate the FEC induction. The increase of sucrose content also can delay the occurrence of somaclonal variation during FEC subculture. Certain amino acids might be helpful for FEC induction under the genotypedependent manner. The rapid cell division and epigenetic regulation by reduced DNA methylation are enhanced during the FEC subculture process and leads to vulnerability of somaclonal variation. This study would shed light for the FEC induction from recalcitrant cultivars and improve the efficiency of FEC-based genetic transformation of cassava.

\section{Author Contributions}

QM carried out the cassava SE and FEC production, molecular, and physiological analysis, and wrote the manuscript. WZ conducted the methylation analysis and sugar measurement. PZ was responsible for the overall concept, experimental design, data analysis, and writing this manuscript. All authors read and approved the manuscript.

\section{Acknowledgments}

We thank Dr. Jun Yang from Shanghai Chenshan Botanical Garden for assistance in DEG analysis. This research was funded by grants from the National Key Technology R\&D Program of China (No. 2015BAD15B01), the National Natural Science Foundation of China (No. 31271775), and the Earmarked Fund for China Agriculture Research System (No. CARS-12-shzp). The data discussed in this publication have been deposited in the Gene Expression Omnibus (GEO) of NCBI under Series record GSE72717.

\section{Supplementary Material}

The Supplementary Material for this article can be found online at: http://journal.frontiersin.org/article/10.3389/fpls.2015. 00824 
Chauhan, R. D., Beyene, G., Kalyaeva, M., Fauquet, C. M., and Taylor, N. (2015). Improvements in Agrobacterium-mediated transformation of cassava (Manihot esculenta Crantz) for large-scale production of transgenic plants. Plant Cell Tiss. Org. Cult. 121, 591-603. doi: 10.1007/s11240-015-0729-Z

Chen, C. C., Fu, S. F., Lee, Y. I., Lin, C. Y., Lin, W. C., and Huang, H. J. (2012). Transcriptome analysis of age-related gain of callus-forming capacity in Arabidopsis hypocotyls. Plant Cell Physiol. 53, 1457-1469. doi: $10.1093 / \mathrm{pcp} / \mathrm{pcs} 090$

Chetty, C. C., Rossin, C. B., Gruissem, W., Vanderschuren, H., and Rey, M. E. C. (2013). Empowering biotechnology in southern Africa: establishment of a robust transformation platform for the production of transgenic industrypreferred cassava. New Biotechnol. 30, 136-143. doi: 10.1016/j.nbt.2012.04.006

Dilokpimol, A., Nakai, H., Gotfredsen, C. H., Appeldoorn, M., Baumann, M. J., Nakai, N., et al. (2011). Enzymatic synthesis of $\beta$-xylosyl-oligosaccharides by transxylosylation using two $\beta$-xylosidases of glycoside hydrolase family 3 from Aspergillus nidulans FGSC A4. Carbohydr Res. 346, 421-429. doi: 10.1016/j.carres.2010.12.010

Elhiti, M., Stasolla, C., and Wang, A. M. (2013). Molecular regulation of plant somatic embryogenesis. In Vitro Cell Dev. Biol. Plant. 49, 631-642. doi: 10.1007/s11627-013-9547-3

Finnegan, E. J., Peacock, W. J., and Dennis, E. S. (2000). DNA methylation, a key regulator of plant development and other processes. Curr. Opin. Genet. Dev. 10, 217-223. doi: 10.1016/S0959-437X(00)00061-7

Fraga, M. F., and Esteller, M. (2002). DNA methylation: a profile of methods and applications. Biotechniques 33, 632-649.

Galbraith, D. W., Harkins, K. R., Maddox, J. M., Ayres, N. M., Sharma, D. P., and Firoozabady, E. (1983). Rapid flow cytometric analysis of the cellcycle in intact plant-tissues. Science 220, 1049-1051. doi: 10.1126/science.220. 4601.1049

Ge, X. X., Chai, L. J., Liu, Z., Wu, X. M., Deng, X. X., and Guo, W. W. (2012). Transcriptional profiling of genes involved in embryogenic, non-embryogenic calluses and somatic embryogenesis of Valencia sweet orange by SSH-based microarray. Planta 236, 1107-1124. doi: 10.1007/s00425-012-1661-7

Gou, J. Y., Miller, L. M., Hou, G., Yu, X. H., Chen, X. Y., and Liu, C. J. (2012). Acetylesterase-mediated deacetylation of pectin impairs cell elongation, pollen germination, and plant reproduction. Plant Cell 24, 50-65. doi: 10.1105/tpc.111.092411

Gresshoff, P., and Doy, C. (1974). Derivation of a haploid cell line from Vitis vinifera and the importance of the stage of meiotic development of the anthers for haploid culture of this and other genera. Z. Pflanzenphys. 73, 132-141. doi: 10.1016/S0044-328X(74)80084-X

Hankoua, B. B., Ng, S. Y. C., Fawole, I., Puonti-Kaerlas, J., Pillay, M., and Dixon, A. G. O. (2005). Regeneration of a wide range of African cassava genotypes via shoot organogenesis from cotyledons of maturing somatic embryos and conformity of the field-established regenerants. Plant Cell Tiss. Org. Cult. 82, 221-231. doi: 10.1007/s11240-005-0514-5

Ikeuchi, M., Sugimoto, K., and Iwase, A. (2013). Plant callus: mechanisms of induction and repression. Plant Cell 25, 3159-3173. doi: 10.1105/tpc.113.116053

Jan, A., Yang, G. X., Nakamura, H., Ichikawa, H., Kitano, H., Matsuoka, M., et al. (2004). Characterization of a xyloglucan endotransglucosylase gene that is up-regulated by gibberellin in rice. Plant Physiol. 136, 3670-3681. doi: 10.1104/pp.104.052274

Lai, Z., and Lin, Y. (2013). Analysis of the global transcriptome of longan (Dimocarpus longan Lour.) embryogenic callus using Illumina paired-end sequencing. BMC Genomics 14:561. doi: 10.1186/1471-2164-14-561

Li, Q., Zhang, S., and Wang, J. (2014). Transcriptome analysis of callus from Picea balfouriana. BMC Genomics 15:553. doi: 10.1186/1471-2164-15-553

Lin, H. C., Morcillo, F., Dussert, S., Tranchant-Dubreuil, C., Tregear, J. W., and Tranbarger, T. J. (2009). Transcriptome analysis during somatic embryogenesis of the tropical monocot Elaeis guineensis: evidence for conserved gene functions in early development. Plant Mol Biol. 70, 173-192. doi: 10.1007/s11103-009-9464-3

Liu, J., Yang, J., Bi, H., and Zhang, P. (2014). Why mosaic? Gene expression profiling of African cassava mosaic virus-infected cassava reveals the effect of chlorophyll degradation on symptom development. J. Integr. Plant Biol. 56, 122-132. doi: 10.1111/jipb.12133
Liu, J., Zheng, Q., Ma, Q., Gadidasu, K. K., and Zhang, P. (2011). Cassava genetic transformation and its application in breeding. J. Integr. Plant Biol. 53, 552-569. doi: 10.1111/j.1744-7909.2011.01048.x

Micheli, F. (2001). Pectin methylesterases: cell wall enzymes with important roles in plant physiology. Trends Plant Sci. 6, 414-419. doi: 10.1016/S13601385(01)02045-3

Miguel, C., and Marum, L. (2011). An epigenetic view of plant cells cultured in vitro: somaclonal variation and beyond. J. Exp. Bot. 62, 3713-3725. doi: 10.1093/jxb/err155

Murashige, T., and Skoog, F. (1962). A revised medium for rapid growth and bioassays with tobacco tissue cultures. Physiol. Plant. 15, 473-497.

Nassar, N. M. A., and Ortiz, R. (2009). "Cassava genetic resources: manipulation for crop improvement," in Plant Breeding Reviews, Vol. 31, ed J. Janick (Hoboken, NJ: John Wiley \& Sons, Inc.), 247-275.

Nyaboga, E., Njiru, J., Nguu, E., Gruissem, W., Vanderschuren, H., and Tripathi, L. (2013). Unlocking the potential of tropical root crop biotechnology in East Africa by establishing a genetic transformation platform for local farmerpreferred cassava cultivars. Front. Plant Sci. 4:526. doi: 10.3389/fpls.2013. 00526

Nyaboga, E. N., Njiru, J. M., and Tripathi, L. (2015). Factors influencing somatic embryogenesis, regeneration, and Agrobacterium-mediated transformation of cassava (Manihot esculenta Crantz) cultivar TME14. Front. Plant Sci. 6:411. doi: 10.3389/fpls.2015.00411

Perera, P. I. P., Ordonez, C. A., Lopez-Lavalle, L. A. B., and Dedicova, B. (2014). A milestone in the doubled haploid pathway of cassava. Protoplasma 251, 233-246. doi: 10.1007/s00709-013-0543-6

Pischke, M. S., Huttlin, E. L., Hegeman, A. D., and Sussman, M. R. (2006). A transcriptome-based characterization of habituation in plant tissue culture. Plant Physiol. 140, 1255-1278. doi: 10.1104/pp.105.076059

Prochnik, S., Marri, P. R., Desany, B., Rabinowicz, P. D., Kodira, C., Mohiuddin, M., et al. (2012). The cassava genome: current progress, future directions. Trop Plant Biol. 5, 88-94. doi: 10.1007/s12042-011-9088-Z

Raemakers, C. J. J. M., Schreuder, M., Pereira, I., Munyikwa, T., Jacobsen, E., and Visser, R. G. F. (2001). Progress made in FEC transformation of cassava. Euphytica 120, 15-24. doi: 10.1023/A:1017574713880

Raemakers, C. J. J. M., Sofiari, E., Taylor, N., Henshaw, G., Jacobsen, E., and Visser, R. G. F. (1996). Production of transgenic cassava (Manihot esculenta Crantz) plants by particle bombardment using luciferase activity as selection marker. Mol. Breed. 2, 339-349. doi: 10.1007/BF00437912

Rival, A., Ilbert, P., Labeyrie, A., Torres, E., Doulbeau, S., Personne, A., et al. (2013). Variations in genomic DNA methylation during the long-term in vitro proliferation of oil palm embryogenic suspension cultures. Plant Cell Rep. 32, 359-368. doi: 10.1007/s00299-012-1369-y

Saladie, M., Rose, J. K. C., Cosgrove, D. J., and Catala, C. (2006). Characterization of a new xyloglucan endotransglucosylase/hydrolase (xth) from ripening tomato fruit and implications for the diverse modes of enzymic action. Plant J. 47, 282-295. doi: 10.1111/j.1365-313X.2006.02784.x

Salvo, S. A., Hirsch, C. N., Buell, C. R., Kaeppler, S. M., and Kaeppler, H. F. (2014). Whole transcriptome profiling of maize during early somatic embryogenesis reveals altered expression of stress factors and embryogenesis-related genes. PLoS ONE 9:e111407. doi: 10.1371/journal.pone.0111407

Sayre, R., Beeching, J. R., Cahoon, E. B., Egesi, C., Fauquet, C., Fellman, J., et al. (2011). The biocassava plus program: biofortification of cassava for sub-Saharan Africa. Ann. Rev. Plant Biol. 62, 251-272. doi: 10.1146/annurevarplant-042110-103751

Schöpke, C., Taylor, N., Cárcamo, R., Konan, N. K., Marmey, P., Henshaw, G., et al. (1996). Regeneration of transgenic cassava plants (Manihot esculenta Crantz) from microbombarded embryogenic suspensions cultures. Nat. Biotechnol. 14, 731-735.

Singh, S. K., Roy, S., Choudhury, S. R., and Sengupta, D. N. (2010). DNA repair and recombination in higher plants: insights from comparative genomics of Arabidopsis and rice. BMC Genomics 11:443. doi: 10.1186/1471-2164-11-443

Soni, R., and Murray, J. A. H. (1994). Isolation of intact DNA and RNA from plant-tissues. Analyt. Biochem. 218, 474-476.

Taylor, N., Chavarriaga, P., Raemakers, K., Siritunga, D., and Zhang, P. (2004). Development and application of transgenic technologies in cassava. Plant Mol. Biol. 56, 671-688. doi: 10.1007/s11103-004-4872-x 
Taylor, N., Gaitan-Solis, E., Moll, T., Trauterman, B., Jones, T., Pranjal, A., et al. (2012). A high-throughput platform for the production and analysis of transgenic cassava (Manihot esculenta) plants. Trop. Plant Biol. 5, 127-139. doi: $10.1007 / \mathrm{s} 12042-012-9099-4$

Taylor, N. J., Edwards, M., Kiernan, R. J., Davey, C. D. M., Blakesley, D., and Henshaw, G. G. (1996). Development of friable embryogenic callus and embryogenic suspension culture systems in cassava (Manihot esculenta Crantz). Nat. Biotechnol. 14, 726-730.

Taylor, N. J., Masona, M. V., Carcamo, R., Ho, T., Schöpke, C., and Fauquet, C. M. (2001). Production of embryogenic tissues and regeneration of transgenic plants in cassava (Manihot esculenta Crantz). Euphytica 120, 25-34. doi: 10.1023/A:1017526814789

Vanderschuren, H., Moreno, I., Anjanappa, R. B., Zainuddin, I. M., and Gruissem, W. (2012). Exploiting the combination of natural and genetically engineered resistance to cassava mosaic and cassava brown streak viruses impacting cassava production in Africa. PLoS ONE 7:e45277. doi: 10.1371/journal.pone.00 45277

Xu, J., Duan, X. G., Yang, J., Beeching, J. R., and Zhang, P. (2013). Enhanced reactive oxygen species scavenging by overproduction of superoxide dismutase and catalase delays post-harvest physiological deterioration of cassava storage roots. Plant Physiol. 161, 1517-1528. doi: 10.1104/pp.112.212803

Yang, J., An, D., and Zhang, P. (2011). Expression profiling of cassava reveals an active process glycolysis/gluconeogenesis. J. Integr. Plant Biol. 53, 193-211. doi: 10.1111/j.1744-7909.2010.01018.x
Zainuddin, I. M., Schlegel, K., Gruissem, W., and Vanderschuren, H. (2012). Robust transformation procedure for the production of transgenic farmer-preferred cassava landraces. Plant Methods 8:24. doi: 10.1186/1746-48 11-8-24

Zhang, P. (2000). Studies on Cassava (Manihot esculenta Crantz) Transformation: Towards Genetic Improvement. Ph.D. Dissertation ETHZ-No.13962. Swiss Federal Institute of Technology, Zurich, Switzerland.

Zhang, P., and Gruissem, W. (2004). "Production of transgenic cassava (Manihot esculenta Crantz)," in Transgenic Crops of the World-Essential Protocols, Chapter 23, ed I. S. Curtis (Dordrecht: Kluwer Academic Publishers), 301-319.

Zhang, P., Potrykus, I., and Puonti-Kaerlas, J. (2000). Efficient production of transgenic cassava using negative and positive selection. Transgenic Res. 9, 405-415. doi: 10.1023/A:1026509017142

Conflict of Interest Statement: The authors declare that the research was conducted in the absence of any commercial or financial relationships that could be construed as a potential conflict of interest.

Copyright (c) $2015 \mathrm{Ma}$, Zhou and Zhang. This is an open-access article distributed under the terms of the Creative Commons Attribution License (CC BY). The use, distribution or reproduction in other forums is permitted, provided the original author(s) or licensor are credited and that the original publication in this journal is cited, in accordance with accepted academic practice. No use, distribution or reproduction is permitted which does not comply with these terms. 